\title{
Leptin, Galectin-3 and Angiotensin II Type I Receptor Polymorphism in Overweight and Obese Patients with Heart Failure - Role and Functional Interplay
}

\author{
Alexandra Dadarlat-Pop $\mathbb{D}^{\prime}$ \\ Dana Pop $\mathbb{D}^{1,2}$ \\ Lucia Procopciuc ${ }^{3}$ \\ Adela Sitar-Taut (iD ${ }^{4}$ \\ Dumitru Zdrenghea ${ }^{1,2}$ \\ Gyorgy Bodizs ${ }^{2}$ \\ Raluca Tomoaia' \\ Diana Gurzau' \\ Florina Fringu' \\ Silvana Susca-Hojda' \\ Anca D Buzoianu (iD ${ }^{5}$ \\ 'Department of Cardiology, "Iuliu Hatieganu" \\ University of Medicine and Pharmacy, Cluj- \\ Napoca, Romania; ' ${ }^{2}$ Department of Cardiology, \\ Clinical Rehabilitation Hospital, Cluj-Napoca, \\ 400347, Romania; ${ }^{3}$ Department of Medical \\ Biochemistry, "Iuliu Hatieganu" University of \\ Medicine and Pharmacy, Cluj-Napoca, Romania; \\ ${ }^{4} 4$ th Medical Clinic, Department of Internal \\ Medicine, "Iuliu Hațieganu" University of \\ Medicine and Pharmacy, Cluj-Napoca, Romania; \\ ${ }^{5}$ Department of Pharmacology, Toxicology and \\ Clinical Pharmacology, "luliu Hatieganu" \\ University of Medicine and Pharmacy, Cluj- \\ Napoca, Romania
}

Background and Aims: Leptin, one of the best-known adipocytes, together with the reninangiotensin-aldosterone system and galectin-3 are important players in inflammation, arterial hypertension and heart failure pathophysiology. Moreover, uninucleotide A1166C polymorphism is associated with hypertension and poor prognosis in heart failure. The aim of the study was to investigate a possible relationship between leptin serum values, specific heart failure biomarkers and the presence of AT1 receptor A1166C polymorphism in overweight and obese heart failure patients.

Methods: The study included 88 consecutive overweight and obese patients admitted for decompensated heart failure. NT-proBNP, MR-proANP, galectin-3 and leptin levels were determined on the arrival day. Genotyping of the A1166C allele - AT1 receptor gene was performed in all patients in order to find variants.

Results: We found a strong positive correlation $(r=0.347, p=0.001)$ between leptin serum concentrations and BMI. Leptin levels were not correlated with heart failure biomarkers (NTproBNP, MR-proANP and galectin-3). All homozygote CC variants were hypertensive, but we registered no significant difference in genetic $\mathrm{AC}$ and $\mathrm{AA}$ variants distribution between hypertensive and normotensive. Leptin was not significantly modified by the presence of potentially pathogenic A1166C-AT 1 receptor genotypes $(\mathrm{AC}+\mathrm{CC})$. But, galectin-3 was found in higher concentrations in patients with heterozygous and homozygous $\mathrm{A} 1166 \mathrm{C}$ mutations.

Conclusion: Overweight and obese patients with heart failure display high leptin serum levels. Leptin does not offer incremental prognostic value in heart failure overweight and obese patients. But, galectin-3 was found in higher concentrations in patients with heterozygous and homozygous A1166C mutations, suggesting a worse prognosis probably due to more advanced cardiac fibrosis.

Keywords: leptin, galectin-3, heart failure, obesity, arterial hypertension, AT1 receptor mutation

\section{Introduction}

Since the discovery of leptin, which certainly revolutionized our knowledge of energy homeostasis, there has been an avalanche of studies regarding the complex pathophysiology and multiple implications of leptin in different scientific areas. Leptin gene (ob gene) mutations predispose to obesity and type II diabetes. ${ }^{1}$
Department of Cardiology, Clinical

Rehabilitation Hospital, 46-50 Viilor

Street, Cluj-Napoca, 400347, Romania

Tel +40744159933

$\mathrm{Fax}+40364818027$

Email pop67dana@gmail.com 
Heart failure is, besides an important hemodynamic disorder, a chronic inflammatory process. Patients diagnosed with heart failure, especially those with heart failure with preserved ejection fraction have various comorbidities, such as overweight or obesity, arterial hypertension, metabolic syndrome. ${ }^{2}$ Excessive adiposity plays a central role in creating an inflammatory vicious circle by secreting numerous pro-inflammatory cytokines known as adipokines. Also, the adipose tissue is an important source of renin-angiotensin-aldosterone system (RAAS) components that contribute to high angiotensin II levels. Moreover, the RAAS acts as a local regulator of adipocyte functions. ${ }^{3}$

So, the interplay between adipokines and RAAS components has a key role in the development and progression of heart failure, but also in discovering new potential therapeutic targets, a subject which is of particular interest because of the epidemic rates of obesity and heart failure worldwide.

There is robust data showing that high leptin levels are associated with an increased risk of heart failure in patients without ischemic coronary disease after adjustment for traditional cardiovascular risk factors, including body mass index (BMI). ${ }^{1}$ The diastolic dysfunction in obese patients may be explained by their hyperleptinemic status, which stimulates metalloproteinases activity in the extracellular matrix with subsequent interstitial fibrosis. ${ }^{4}$ On the other hand, other studies provide enough evidence that hyperleptinemia is associated with a favorable prognosis in heart failure by neutralizing the myocardial effects of other proinflammatory cytokines.,

Therefore, leptin's involvement in the development and progression of heart failure remains extremely controversial. The relationship between leptin and the RAAS is bidirectional. Leptin not only stimulates sympathetic nervous system activation and angiotensin-dependent mechanisms, but it also seems to be a major driver in the aldosterone production in obese patients. ${ }^{6}$ This explains mineralocorticoid excessive concentrations in obese heart failure patients and its major contribution to the development of hypertension.

There are several biomarkers- NT-proBNP, galectin-3 (Gal-3), MR-proANP that help us in the diagnosis of heart failure, especially in the presence of other conditions, such as obesity. ${ }^{7,8}$

Gal-3 is one of the 14 members of the lectin family. It is a novel biomarker of heart failure, being strongly associated with inflammation and fibrosis. Gal-3 binds various betagalactosides through its carbohydrate recognition domain with secondary biological effects, studies showing its major involvement in the pathophysiology of heart failure. ${ }^{9}$ The
PRIDE trial showed significantly higher Gal-3 values in patients with heart failure than in those without heart failure. ${ }^{10}$ Studies showed that Gal-3 is involved in target organ damage in patients with hypertension. There is evidence that Gal-3 is also a modulator of adipogenesis, obese patients having higher concentrations than their lean counterparts, but the links between Gal-3, obesity, hypertension and chronic heart failure remain unclear. ${ }^{11,12}$

An extensively studied gene in the cardiovascular disease pathogenesis is the angiotensin II subtype 1 receptor (AT1) gene. The uninucleotide AT1- A1166C polymorphism is found in the 3 'UTR region. Studies have shown that A1166C polymorphism is associated with poor prognosis in heart failure by having significant consequences on ventricular remodeling. ${ }^{13,14}$ Detrimental effects of angiotensin II may be, at least partially mediated by Gal-3, which stimulates proinflammatory adhesion molecules and cytokines, leading to cardiac fibrosis and arterial hypertension.

The goal of the study was to investigate the relationship between leptin, Gal-3 serum values and the presence of uninucleotide AT1- A1166C polymorphism in overweight or obese patients with heart failure with or without arterial hypertension.

\section{Methods}

\section{Study Population}

Our study complied with the declaration of Helsinki and was approved by the hospital ethics review board of the Clinical Rehabilitation Hospital, Cluj-Napoca, Romania. We enrolled 88 consecutive patients admitted to the Cardiology service for decompensated chronic heart failure. All subjects included in the current study were overweight or obese, having a BMI $\geq 25 \mathrm{~kg} / \mathrm{m} 2$. Heart failure was defined according to the current guidelines. ${ }^{15}$ Patients were excluded if they had recent myocardial infarction, infectious endocarditis, myocarditis or stroke, unstable angina, significant valvular heart disease, end stage hepatic or renal disease, chronic inflammatory or neoplastic diseases. Also, patients with recent cardiac or major noncardiac surgery were excluded. All patients were informed about the purpose of this study and gave their written consent.

Medical history, baseline demographic and clinical variables were assessed, as shown in Table 1. ECG and standard transthoracic echocardiography were performed in all patients. 
Table I Baseline Characteristics of the Patients

\begin{tabular}{|l|c|}
\hline Characteristic & Value \\
\hline Women (\%) & $5 I$ \\
Age (years) & $69.4 \pm 9.4$ \\
Systolic blood pressure (mmHg) & $142.5 \pm 22.7$ \\
Current smoking (\%) & 34 \\
Diabetes mellitus (\%) & 38 \\
BMI (kg/m2) & $36(27-48)$ \\
Antihypertensive treatment (\%) & $73 \%$ \\
History of atrial fibrillation (AF) (\%) & 52 \\
Left ventricular ejection fraction (mean \pm SD) (\%) & $45 \pm 12$ \\
eGFR (mL/min/I.73 m2) & $84 . I \pm 28.8$ \\
NYHA functional class I-II (\%) & 36 \\
NYHA functional class III-IV (\%) & 63 \\
History of myocardial infarction (\%) & 18 \\
Peptic ulcer (\%) & 25 \\
\hline
\end{tabular}

Notes: Data are \% for binary traits and means \pm SD for continuous traits.

Women represented $51 \%$ of the included patients, and there was a high prevalence of ischemic heart disease, arterial hypertension and diabetes mellitus among them. $73 \%$ of patients were hypertensive.

We followed the methods of Dadarlat et al. 2019. ${ }^{16}$

\section{Determination of Specific Heart Failure Biomarkers}

NT-proBNP levels were determined on the arrival day using the chemiluminescence method. The cut-off value for NT-proBNP was $125 \mathrm{pg} / \mathrm{mL}$. CUSABIO Human Midregional Pro-Atrial Natriuretic Peptide (MR-proANP) and BOSTER Human Galectin-3/LGALS3 were used for the ELISA determination of MR-proANP and Gal-3 levels. The cut-off values for MR-proANP and Gal-3 were $120 \mathrm{pmol} / \mathrm{L}$ and $17.8 \mathrm{ng} / \mathrm{mL}$, respectively. ${ }^{15}$

\section{Determination of Leptin Serum Concentration}

Blood samples required for serum leptin concentration determination were collected on the admission day after the informed consent of patients regarding the research scope and the confidentiality of the results. Serum was separated by centrifugation at $1500 \mathrm{~g}$ for 10 minutes at $4^{\circ} \mathrm{C}$, then was transferred into $1 \mathrm{~mL}$ cryotubes, and stored at $-70^{\circ} \mathrm{C}$ for later analysis. Leptin levels were determined using the ELISA method (Human Leptin BioVendor kit), with an intra-assay coefficient of variation (CV) of $5.9 \%$ $(\mathrm{n}=8)$, an interassay $\mathrm{CV}$ of $5.6 \%(\mathrm{n}=6)$ and a sensitivity of $0.2 \mathrm{ng} / \mathrm{mL}$.
Calibration of all assays were performed according to the manufacturer's recommendations.

\section{Determination of ATI Receptor Uninucleotide AI I66C Polymorphism DNA Isolation}

Genomic DNA was extracted from $2 \mathrm{~mL}$ venous blood using EDTA vacutainers; the concentration was determined.

\section{PCR Amplification}

The amplification of the fragment of interest was done according to the method of Takemoto et al $^{17}$ modified in the Laboratory of Medical Biochemistry, University of Medicine and Pharmacy „Iuliu Hatieganu”, Cluj-Napoca. The amplification mixture was comprised of $20 \mathrm{ng}$ of genomic DNA, $0.2 \mu \mathrm{M}$ primers forward (5'-ATAATGT AAGCTCATCCACC-3') and reverse (5'-GAGATTGC ATTTCTGTCAGT-3'), $200 \mathrm{mM}$ dNTP (dATP, dGTP, dCTP, dTTP), $2.0 \mathrm{mM} \mathrm{MgCl} 2,2 \mathrm{U}$ Taq polymerase. Amplification was performed in $25 \mu \mathrm{L}$ reaction mixture in a C1000TM -Thermal Cycler (Bio- Rad Laboratories Inc. 1000 Alfred Nobel Drive, Hercules, California, USA) using the following amplification program: $0.6 \mathrm{sec}$ denaturation at $95^{\circ} \mathrm{C}$, followed by 34 cycles of amplification with $0.2 \mathrm{sec}$ denaturation at $95^{\circ} \mathrm{C}, 0.2 \mathrm{sec}$ primers hybridization at $50^{\circ}$ $\mathrm{C}$ and $0.2 \mathrm{sec}$ elongation primers at $72^{\circ} \mathrm{C}$. The amplification cycles were followed by $0.3 \mathrm{sec}$ final elongation at $72^{\circ}$ C. The amplified fragment had $350 \mathrm{pb}$.

\section{Amplified Fragments Electrophoresis}

The specificity and efficiency of the amplification reaction was checked by performing a $2 \%$ agarose gel electrophoresis stained with $10 \mathrm{mg} / \mathrm{mL}$ ethidium bromide. The amplified fragment was visualized in UV light (GelVue Transiluminator and DigiGenius PS G9 Gel Documentation and Analysis System, Syngene, Beacon House Nuffield Road Cambridge, United Kingdom, www.syngene.com). A molecular weight marker pBR322HaeIII Digest was used to establish the band profile.

\section{Enzyme Digestion}

Digestion of the amplified fragment of $350 \mathrm{bp}$ was performed by incubating $5 \mu \mathrm{L}$ of PCR product with $5 \mathrm{U}$ of HpyF31 restriction enzyme (DdeI) at $10 \mathrm{U} / \mu \mathrm{L}$ in Tango buffer with the following composition: $10 \mathrm{mM}$ Tris/HCl $\left(\mathrm{pH} 7.4\right.$ at $\left.25^{\circ} \mathrm{C}\right), 100 \mathrm{mM} \mathrm{KCl}, 1 \mathrm{mM}$ EDTA. 1 mM DTT, 
$0.2 \mathrm{mg} / \mathrm{mL}$ BSA and $50 \%$ glycerol. The digestion mixture was incubated for 3 hours at $37^{\circ} \mathrm{C}$. The AT1A1166C polymorphism introduces a restriction site for the HpyF31 enzyme (DdeI). The normal A1166 allele forms a 350 bp fragment by enzymatic digestion, while the C1166 mutant allele forms two fragments of 211 and $139 \mathrm{bp}$.

\section{Electrophoresis of Digested Fragments}

Verification of enzyme digestion specificity was done by performing a $3 \%$ agarose gel electrophoresis stained with $10 \mathrm{mg} / \mathrm{mL}$ ethidium bromide. Visualization of the strip profile obtained by enzymatic digestion was done in UV light.

Reagents for genomic DNA isolation were provided by Zymo Research (Zymo Research Corporation, Irvine, California, U.S.A.). The PCR amplification reagents were derived as follows: nucleotides (dNTP) and Taq polymerase were provided by Fermentas (Thermo Fisher Scientific TR Limited, Waltham, Massachusetts, United States, www.thermoscientific.com/onebio), the primers and the restriction enzyme were provided by Invitrogen (Thermo Fisher Scientific TR Limited, Waltham, Massachusetts, United States, www.thermoscientific.com/onebio).

\section{Statistical Analysis}

We used the SPSS Statistics for Windows software program (version 23, IBM Corporation, Armonk, NY, USA). We calculated the mean values for continuous variables including standard deviations and median values. Numbers and percentages represent the categorical variables. For comparisons between the selected groups we used the following tests: the ANOVA test; the Kruskal-Wallis test and the Chi-square test. For the evaluation of independent predictive factors for NT-proBNP, Gal-3 and MR-proANP we performed multivariate analysis, taking into consideration multiple factors, such as: age, sex, diabetes mellitus, arterial hypertension, left ventricular ejection fraction, $\mathrm{AF}$, creatinine clearance, BMI. A P value $<0.05$ was defined as statistically significant.

\section{Results}

Among the study participants, $25.4 \%$ had heart failure with reduced ejection (HFrEF), 29.4\% had heart failure with mid-range ejection fraction (HFmrEF) and 45.2\% heart failure with preserved ejection fraction (HFpEF).

\section{Leptin}

Leptin and Gal- 3 levels did not follow a statistical normal distribution. The median serum leptin concentration was $25 \mathrm{ng} / \mathrm{mL}$. Leptin was found to display a strong positive correlation with BMI $(r=0.347, p=0.001)$. Figure 1 illustrates a linear positive correlation between BMI and leptin serum levels in the general population, as well as in patients with and without AF.

There was no statistically significant difference in serum leptin levels in hypertensive patients and those without hypertension, $\mathrm{p}=0.08$.

Serum leptin levels were not significantly higher in females versus males $(29.2 \mathrm{ng} / \mathrm{mL}$ vs $21.65 \mathrm{ng} / \mathrm{mL}$ in, $\mathrm{p}=0.13$, by using the Mann-Whitney test), as you can see in Figure 2. BMI mean was comparable in women and men $(36.22 \pm 4.46 \mathrm{~kg} / \mathrm{m} 2$ vs $35.65 \pm 4.52 \mathrm{~kg} / \mathrm{m} 2)$.

No significant difference in serum leptin levels was observed between patients with AF (median value 26.35 $\mathrm{ng} / \mathrm{mL}$ ) and those in sinus rhythm (median value $24.20 \mathrm{ng} /$ $\mathrm{mL}), \mathrm{p}=\mathrm{NS}$ - Figure 2 .

There was no correlation between serum leptin levels and left ventricular ejection fraction $(r=0.183, p=0.08)$, regardless of the presence of AF.

The values of the natriuretic peptides- NT-proBNP and MR-proANP were significantly increased in the overall population. Analysis of the relationship between leptin and specific heart failure biomarkers has yielded some interesting results. Leptin serum levels did not correlate with NT-proBNP, MRproANP and Gal-3 levels, respectively - Table 2 .

\section{Gal-3}

The median serum Gal-3 concentration was $34 \mathrm{ng} / \mathrm{mL}$. A notable finding is that Gal-3 levels were not influenced by BMI. No sex differences in the levels of Gal-3 were found $(41.5 \mathrm{ng} / \mathrm{mL}$ in women vs $26.5 \mathrm{ng} / \mathrm{mL}$ in men, $\mathrm{p}=$ 0.11 , by using the Mann-Whitney test).

The median value of Gal-3 in hypertensive patients was $41 \mathrm{ng} / \mathrm{mL}$ vs $34 \mathrm{ng} / \mathrm{mL}$ in patients without hypertension.

Consequently, in what concerns the relationship between the respective heart failure biomarker, sex, and the presence of AF, we found the following Gal-3 serum levels: female patients in sinus rhythm vs those with AF $-43 \mathrm{ng} / \mathrm{mL}$ vs $35 \mathrm{ng} / \mathrm{mL}, \mathrm{p}=\mathrm{NS}$; men in sinus rhythm vs those with $\mathrm{AF}-34.25 \mathrm{ng} / \mathrm{mL}$ vs $23 \mathrm{ng} / \mathrm{mL}$, $\mathrm{p}=\mathrm{NS}$; women in sinus rhythm vs men in sinus rhythm$43 \mathrm{ng} / \mathrm{mL}$ vs $34.25 \mathrm{ng} / \mathrm{mL} \mathrm{p}=\mathrm{NS}$; women with AF vs men with $\mathrm{AF}-35 \mathrm{ng} / \mathrm{mL}$ vs $23 \mathrm{ng} / \mathrm{mL} \mathrm{p}=\mathrm{NS}$. There 
RELATIONSHIP BETWEEN LEPTIN AND BODY MASS INDEX

( $95 \%$ CONFIDENCE)
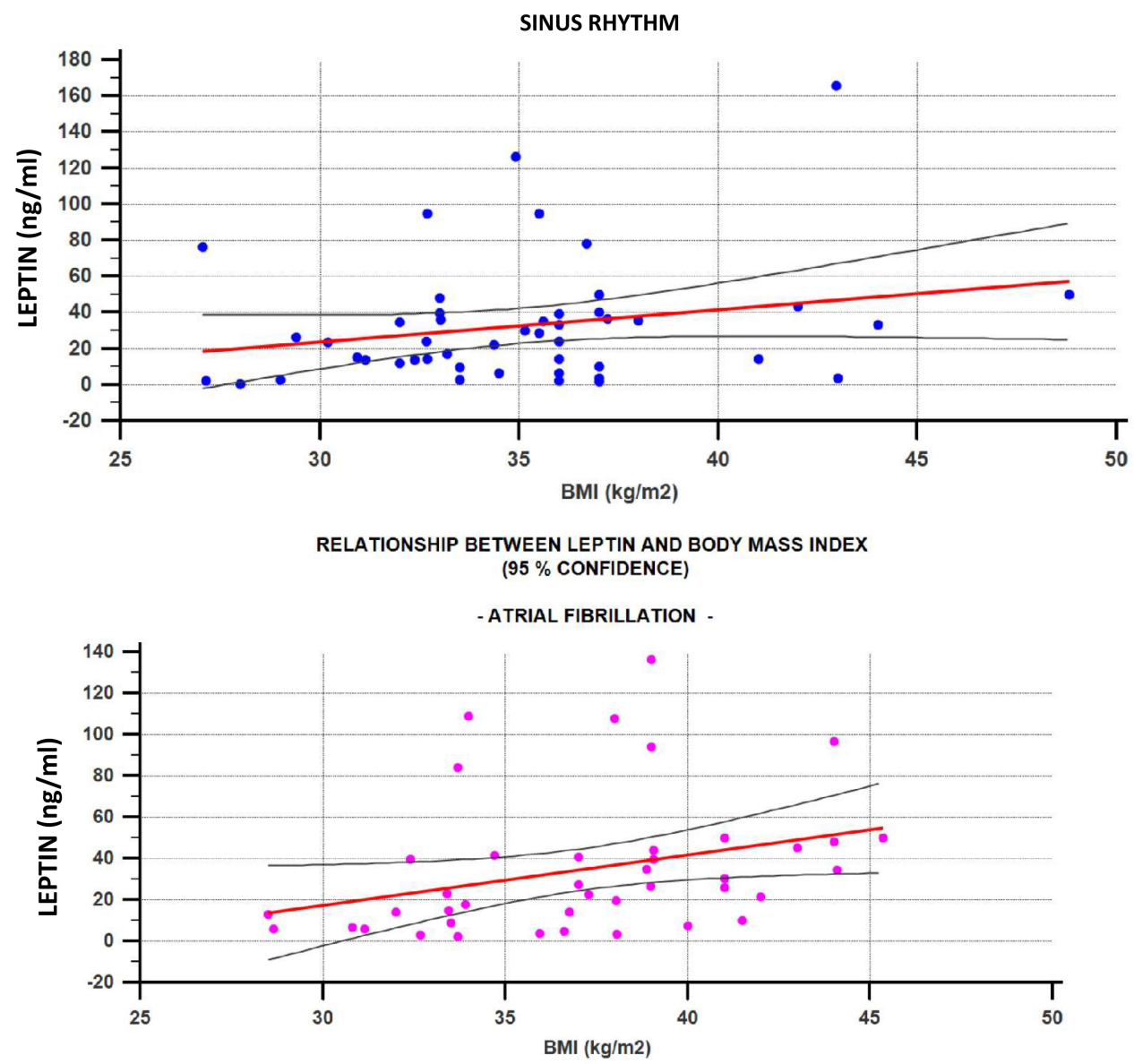

Figure I Correlation between leptin levels and BMI.

was no correlation between serum Gal-3 levels and left ventricular ejection fraction $(\mathrm{r}=0.336, \mathrm{p}=0.2)$.

\section{ATI-AII66C Receptor Polymorphism}

The genotype distribution of AT1-A1166C receptor polymorphism found in the patients included in the study was as follows: $\mathrm{AC}$ in 44 of the patients representing $50 \%, \mathrm{CC}$ in 5 of the patients (5.68\%) and AA in 39 of the patients (44.3\%) Thus, $55.68 \%$ of the patients had potentially pathogenic mutations (AC-heterozygote and CC-positive). The mutations with pathogenic potential were more likely to be found in patients with AF than in those in sinus rhythm: $65.21 \mathrm{vs}$ 45.23\%. In overall population, patients carrying AT1 AC and $\mathrm{CC}$ genotypes did not show significantly higher serum leptin values than AA negative subjects, when using the Kruskal Wallis test - Table 3 and Figure 2.

After evaluating the association of AT1 A1166C polymorphism with leptin levels, further analysis was extended to look for the association of AT1 A1166C polymorphism with Gal- 3, a specific heart failure biomarker. An interesting finding is that carriers of potentially A1166C pathogenic mutations (AC and CC) had significantly higher Gal-3 levels as compared with negative AA patients $(48.76 \pm 50.29$ vs $32.17 \pm 23.01 \mathrm{ng} / \mathrm{mL}, \mathrm{p}=0.03)$. Median Gal-3 levels in subjects with $\mathrm{AC}$ and $\mathrm{CC}$ genotypes were $41.5 \mathrm{ng} / \mathrm{mL}$ vs $25.5 \mathrm{ng} / \mathrm{mL}$ in AA type genotype patients.

We also analyzed the A1166C pathogenic mutations distribution in hypertensive heart failure patients. As you can see in Figure 3, all homozygote $\mathrm{CC}$ variants were hypertensive, but we registered no significant difference in genetic $\mathrm{AC}$ and $\mathrm{AA}$ variants distribution between hypertensive and normotensive.

As you can see in Table 1, the prevalence of diabetes mellitus in our study was $38 \%$. Among the diabetic subjects, $28 \%$ had HFrEF, $29.7 \%$ HFmrEF and $40.3 \%$ HFpEF. NTproBNP levels were significantly higher in diabetic patients 

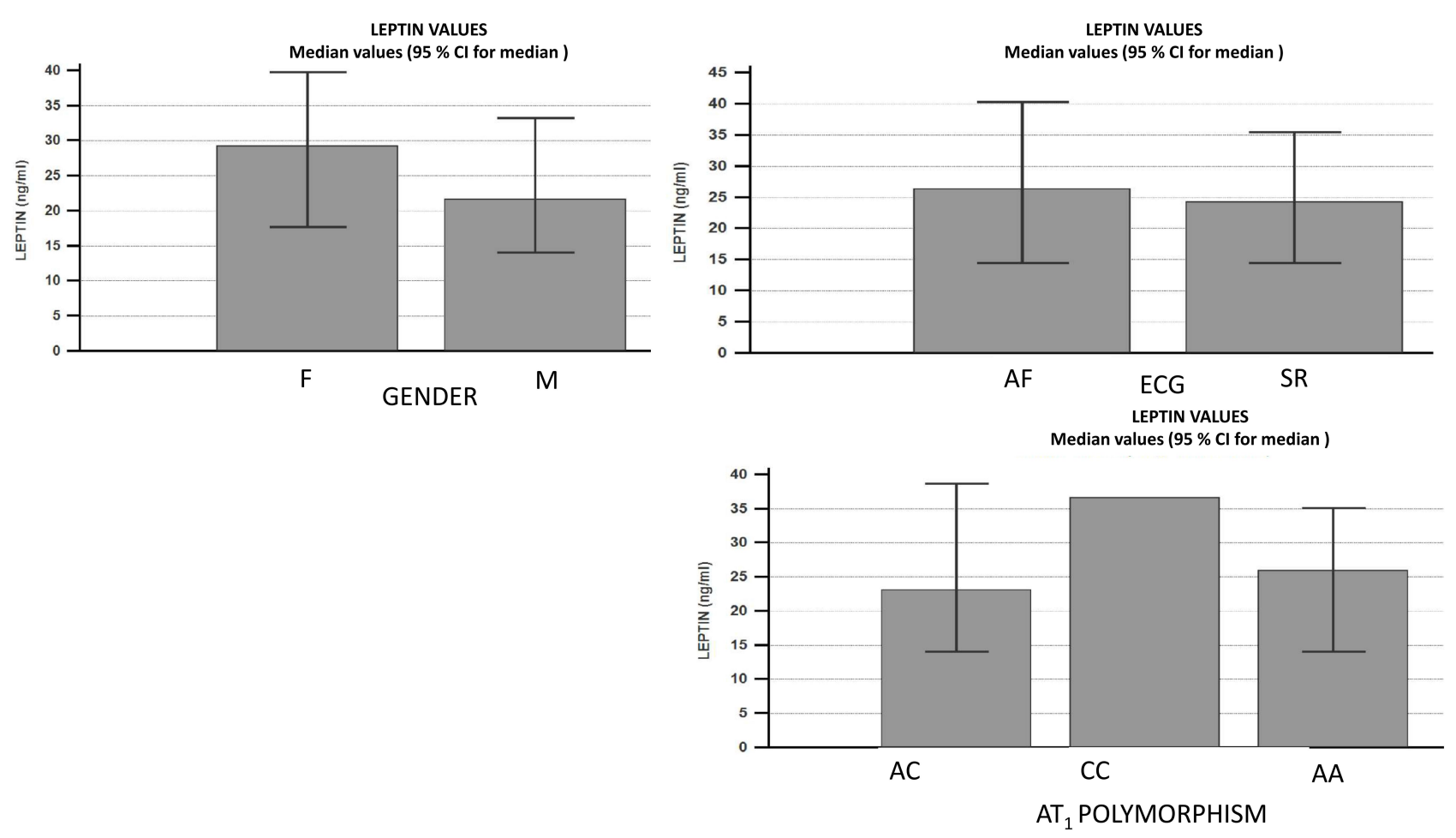

Figure 2 ECG, sex and ATI polymorphism- based differences in leptin serum levels.

with HFrEF than in those with HFmrEF or HFpEF $(p=0.014)$. Serum leptin levels were not significantly different in diabetic patients versus non-diabetic $(23.3 \mathrm{ng} / \mathrm{mL}$ vs 26 $\mathrm{ng} / \mathrm{mL}$ in, $\mathrm{p}=0.86$, by using the Mann-Whitney test). Also, no significant differences in serum Gal-3 and MR-proANP levels were observed between patients with diabetes mellitus (median value $33 \mathrm{ng} / \mathrm{mL}$ and $257.5 \mathrm{pmol} / \mathrm{l}$ ) and those without diabetes (34.7 $\mathrm{ng} / \mathrm{mL}, \mathrm{p}=0.59$ and $227.5 \mathrm{pmol} / \mathrm{l}, \mathrm{p}=0.96)$.

Among diabetic subjects, $58.8 \%$ had potentially pathogenic mutations (AC-heterozygote and $\mathrm{CC}$ homozygote)- as you can see in Table 4. We did not find differences in terms of AT1-A1166C genotype distribution between patients with and those without diabetes mellitus $(\mathrm{p}=0.58)$.

\section{Treatment}

All patients received in-hospital treatment recommended by current guidelines [15]. At discharge, the main classes recommended were: angiotensin-converting enzyme inhibitors (ACEIs)/sartans (in case of ACEI intolerance or cough) along with beta-blockers, mineralocorticoid receptor antagonists (MRAs), ivabradine. The sacubitril/valsartan combination was prescribed for patients with HFrEF. Obviously, patients with heart failure and AF received anticoagulants, $60 \%$ of them were on direct acting nonvitamin $\mathrm{K}$ antagonist oral anticoagulants. Moreover, patients with AF received more often beta-blockers than those in sinus rhythm $(\mathrm{p}=0.05)$ - as you can see in Table 5 .

Patients treated with MRAs did not show lower levels of Gal-3 compared to those without this treatment $(\mathrm{p}=0.1)$. In terms of AT1 receptor genetic polymorphism, 55.68\% of the study population presented $\mathrm{AC}$ and $\mathrm{CC}$ genotypes. Of them, $77.55 \%$ received therapy with angiotensin-aldosterone inhibitors: $63.15 \%$ ACEIs and 36.84\% sartans. As you can observe, not all patients with potentially pathogenic AT1-

Table 2 Correlation Between Leptin Levels and Heart Failure Biomarkers (NT-proBNP, MR-proANP and Gal-3 Levels)

\begin{tabular}{|l|l|l|l|l|}
\hline Heart Failure Biomarkers & Spearman R (Raw Data) & P value & Pearson R (Log-Transformed Data) & P value \\
\hline NT-proBNP & -0.101 & 0.35 & -0.098 & 0.365 \\
MR-proANP & -0.002 & 0.987 & 0.005 & 0.962 \\
Gal-3 & 0.027 & 0.805 & -0.003 & 0.977 \\
\hline
\end{tabular}


Table 3 Leptin Levels: Median and 25th-75th Percentile and ATI Receptor AII66C Gene Polymorphism

\begin{tabular}{|l|l|l|l|}
\hline Leptin Concentrations $\mathbf{( n g / m L})$ & AC Genotype & CC Genotype & AA Genotype \\
\hline 25th centile & $9.71[4.64-16.5]$ & 20.67 & $8.05[3.53-22.64]$ \\
Median & $23.1[14-38.62]$ & 36.6 & $25.9[14.03-35.06]$ \\
75 th centile & $42.45[29.97-58.25]$ & 57.07 & $40.92[32.09-78.67]$ \\
\hline
\end{tabular}

Notes: Due to the skewed distribution, leptin levels are given as median (interquartile range) and $95 \%$ confidence interval. Because of the small number of patients with CC genotype, $95 \%$ confidence interval was not calculated.

A1166C receptor polymorphism were treated with inhibitors of the renin-angiotensin system.

\section{Discussion}

Usually, overweight and obese patients have high levels of circulating leptin, which seems to correlate with their BMI, as demonstrated in our study. The aforementioned finding is in line with the available data. ${ }^{14}$ The patients' hyperleptinemic status may be explained by the peripheral leptin resistance, a phenomenon similar to "insulin resistance" in diabetes mellitus. Moreover, they both frequently coexist in obese patients. High serum leptin levels lead to endothelial dysfunction, oxidative stress, cardiomyocyte hypertrophy, and vascular smooth muscle cell proliferation, ${ }^{18}$ mechanisms by which obesity may impact the development and progression of heart failure with important clinical and therapeutic implications. The controversial role of leptin in obese heart failure patients is addressed in the following section below.

While being abundantly produced by white adipocytes, leptin is also synthesized and secreted by peripheral organs such as the heart. Leptin's functional receptors a and b (OB-Ra, $\mathrm{OB}-\mathrm{Rb}$ ) are highly expressed on the cardiomyocyte surface, suggesting its multiple effects on the cardiovascular system. ${ }^{19}$ There is evidence that high leptin levels may be predictors of developing heart failure independent of BMI in patients without pre-existing coronary artery disease. ${ }^{20}$ Elevated circulating levels of leptin in heart failure patients independent of their BMI are a marker of severity and clinical instability, and also it seems to predict adverse events. ${ }^{1,6}$ Leptin mediates sodium retention and promotes volume overload via neprilysin hyperactivity leading to ventricular remodeling [6], especially left ventricular hypertrophy. ${ }^{21}$ In our study, leptin levels were high, with a median value of $25 \mathrm{ng} / \mathrm{mL}$, but they did not correlate with markers of heart failure severity, such as specific heart failure biomarkers (NT-proBNP, MR-proANP and Gal-3) or left ventricular ejection fraction. In light of the study by Khafaji et al, leptinemia correlates with left ventricular ejection fraction, but only in patients with acute myocardial infarction. ${ }^{22} \mathrm{On}$ the other hand, there is data correlating hyperleptinemia found in obese heart failure patients with a better prognosis ${ }^{23}$ by attenuating cardiomyocyte apoptosis and having vasodilatory effects via nitric oxide production. ${ }^{24}$

Alternatively, other studies have shown reduction in serum leptin values in patients with advanced heart failure, especially in those with cardiac cachexia because of the

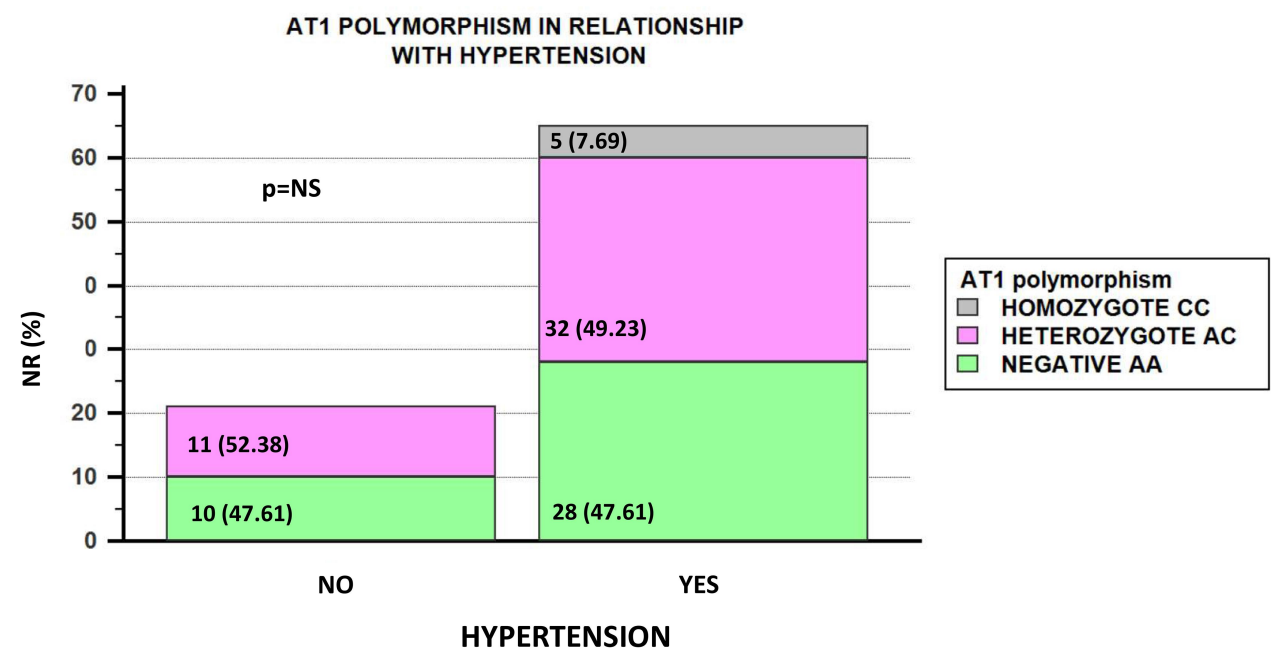

Figure 3 ATI AII66C genetic polymorphism distribution in patients with or without hypertension. 
Table 4 ATI-AII66C Receptor Polymorphism Distribution in Patients with and without Diabetes Mellitus

\begin{tabular}{|l|l|l|l|}
\hline $\begin{array}{l}\text { ATI-AI I66C } \\
\text { Genotypes }\end{array}$ & $\begin{array}{c}\text { Diabetic } \\
\text { Patients } \\
\text { No. (\%) }\end{array}$ & $\begin{array}{c}\text { Non-Diabetic } \\
\text { Patients } \\
\text { No. (\%) }\end{array}$ & P value \\
\hline AC & $17(50)$ & $27(50)$ & 0.58 \\
CC & $3(8.82)$ & $2(3.7)$ & \\
AA & $14(41.17)$ & $25(46.29)$ & \\
\hline
\end{tabular}

reduced fat tissue. ${ }^{25}$ The basal metabolic rate is increased in these patients.

Typically, women have higher leptin values than men, ${ }^{25}$ probably due to sex hormones effects. We have found no gender-based differences in circulating leptin levels in the studied sample. A possible explanation could be that they had similar BMIs. Alternatively, another explanation could be that in the presence of heart failure, gender differences in circulating leptin levels observed in healthy subjects may not be found.

But, besides the above-mentioned metabolic changes involved in the pathophysiology of both heart failure and hypertension, the interaction with genetic factors plays an important role as well. Among the most studied genetic variants with pathophysiological significance in heart failure and hypertension are the polymorphisms in RAAS genes. Some of them may increase the risk of heart failure and arterial hypertension, and others affect the therapeutic response to neurohormonal antagonists. Angiotensin II is known for its important vasoconstrictor effects via AT1 receptors, thus leading to increased cardiac afterload. Antagonists of AT1 are now widely used in the treatment of both arterial hypertension and heart failure. There are studies showing that single polymorphism AT1 receptor contributes to an inherited predisposition towards arterial hypertension development. There are studies showing that A1166C molecular variant is associated with a modest increased risk of hypertension. ${ }^{26}$ On the other hand, other studies show no association of A1166C polymorphism and hypertension. ${ }^{27,28}$ Age, sex and ethnic origin may be important factors influencing the relationship between AT1A1166C polymorphism and arterial hypertension. ${ }^{28}$ In this study although all homozygote $\mathrm{CC}$ variants were hypertensive, there was no significant difference in genetic $\mathrm{AC}$ and $\mathrm{AA}$ variants distribution between hypertensive and normotensive.

Also, the potentially pathogenic AT1-A1166C genotypes are associated with poor prognosis in heart failure patients because of important ventricular remodeling effects. ${ }^{29,30}$ Studies have also shown an increase in the density of AT1 receptors after myocardial infarction. ${ }^{31}$ Enhanced AT1 receptor signaling may be responsible for arteriolar vasoconstriction and significant pressure increase, leading to left ventricular dysfunction. Moreover, these effects are potentiated in obese patients due to the increased expression of the AT1 receptors in the excessive adipose tissue. Also, another phenomenon described in obese population regards angiotensin II binding defects to AT1 receptors. ${ }^{32}$ In the current study we have raised the hypotheses that overweight and obese heart failure patients with A1166C potentially pathogenic variants, with subsequently pronounced deleterious angiotensin II cardiac effects, would present higher levels of severity biomarkers. More than half of the overweight and obese patients with heart failure presented potentially

Table 5 Differences in Medication Management Based on the Presence of AF

\begin{tabular}{|l|c|c|c|}
\hline Pharmacotherapy & Patients with AF & Patients without AF & P value \\
\hline ACEls & $23(50.0 \%)$ & $20(43.5 \%)$ & 0.377 \\
Sartans & $12(26.1 \%)$ & $14(30.4 \%)$ & 0.631 \\
Sacubitril/valsartan & $2(4.3 \%)$ & $1(2.2 \%)$ & 0.264 \\
Beta-blockers & $39(84.8 \%)$ & $33(71.7 \%)$ & 0.05 \\
Diuretics & $21(45.7 \%)$ & $22(47.8 \%)$ & 0.883 \\
Nitrates & $6(13.0 \%)$ & $4(8.7 \%)$ & 0.289 \\
Calcium channel blockers & $5(10.9 \%)$ & $5(10.9 \%)$ & 1.000 \\
Amiodarone & $9(19.6 \%)$ & $10(21.7 \%)$ & 0.859 \\
Propafenone & $3(6.5 \%)$ & $1(2.2 \%)$ & 0.078 \\
Digoxin & $10(21.7 \%)$ & $0(0.0 \%)$ & \\
Acenocumarol & $16(34.8 \%)$ & $1(2.2 \%)$ & 0.000 \\
Apixaban & $10(21.7 \%)$ & $0(0.0 \%)$ & 0.000 \\
Rivaroxaban & $11(23.9 \%)$ & $3(6.5 \%)$ & 0 \\
Dabigatran & $7(15.2 \%)$ & $0.0 \%)$ & \\
\hline
\end{tabular}

Note: Data in bold indicate statistically significant results. 
pathogenic mutations $(\mathrm{AC}+\mathrm{CC})$. Also, even though serum leptin values were higher in $\mathrm{CC}$ homozygous patients, there were no statistically significant differences compared to AAnegative or heterozygous AC patients. Leptin, Gal- 3, NTproBNP and MR-proANP levels were not significantly different in patients with and without hypertension.

The main finding of the present study indicates that leptin is not an accurate independent prognostic tool in patients with heart failure who are overweight or obese. Also, another interesting finding of our subgroup analysis is that Gal-3, an important marker of inflammation and fibrosis in heart failure, was found in higher concentrations in patients with heterozygous and homozygous A1166C mutations. This suggests that overweight or obese heart failure patients with potentially pathogenic A1166C mutations $(\mathrm{AC}+\mathrm{CC})$ of the AT1 receptor have a worse prognosis than their AA negative counterparts. Also, Gal-3 was independent of BMI. Moreover, studies have shown that Gal-3 is the most accurate risk predictor of adverse events within 5 years in patients with heart failure with preserved ejection fraction. ${ }^{33}$ In addition, high Gal-3 serum levels in carriers of A1166C pathogenic mutations reflect significant myocardial inflammation and fibrosis. This may represent an important link between obesity, heart failure, and elevated Gal-3 levels via proinflammatory pathways. Moreover, excessive Gal-3 concentrations could also stimulate the proliferation of adipose tissue, leading to a chronic inflammatory vicious circle. Also, taking into account that more than a half of our patients carried potentially pathogenic A1166C mutations and high Gal-3 concentrations, and extrapolating these results, we believe that the ongoing clinical trials with Gal3 inhibitors as a new potential treatment in heart failure could represent a real opportunity to further reduce heart failure hospitalizations and mortality.

However, these results could have been influenced by the relatively small number of patients included in the study.

\section{Conclusions}

In conclusion, overweight and obese patients with heart failure display high leptin serum levels, these values being directly correlated with their BMIs. Leptin levels did not correlate with specific heart failure biomarkers. So, in overweight and obese patients with heart failure leptin does not serve as an accurate tool for diagnostic and prognostic assessment. But, Gal-3 was found in higher concentrations in patients with heterozygous and homozygous A1166C mutations, suggesting a worse prognosis probably due to more advanced cardiac fibrosis. Even though, all CC AT1- A1166C homozygote variants were hypertensive, $\mathrm{AC}$ and $\mathrm{AA}$ genotype distribution was not significantly different in hypertensive and normotensive heart failure patients. But novel antagonistic therapeutic strategies targeting Gal-3 could be extremely useful in the management of hypertension and heart failure.

\section{Abbreviations}

ACEIs, angiotensin-converting enzyme inhibitors; AF, atrial fibrillation; AT1, angiotensin II subtype 1 receptor; BMI, body mass index; Gal-3, galectin-3; MCP-1, monocyte chemoattractant protein; MRAs, mineralocorticoid receptor antagonists; NS, not statistically significant; NR, number; PAI-1, plasminogen type 1 inhibitor; RAAS, renin-angiotensin-aldosterone system.

\section{Data Sharing Statement}

The data used to support the findings of this study are available from the corresponding author upon request.

\section{Ethics Approval}

The institutional ethics committee of "Iuliu Hatieganu" University of Medicine and Pharmacy approved the study protocol (permission code: 119/13.03.2017). The study was carried out respecting the Declaration of Helsinki.

\section{Consent to Participate}

The subjects included in the current study gave their consent and permit the publication of this paper.

\section{Acknowledgments}

This paper was published under the frame of European Social Found, Human Capital Operational Programme 2014-2020, project no. POCU/380/6/13/125171.

\section{Author Contributions}

All authors made substantial contributions to conception and design, acquisition of data, or analysis and interpretation of data; took part in drafting the article or revising it critically for important intellectual content; agreed to submit to the current journal; gave final approval of the version to be published; and agree to be accountable for all aspects of the work.

\section{Funding}

The study was funded by the institutional research grant "Iuliu Hatieganu" University of Medicine and Pharmacy, Cluj-Napoca, Romania (PCD 2016- No. 7690/39/ 15.04.2016). 


\section{Disclosure}

The authors reported no conflicts of interest for this work and have no financial or proprietary interests in any material discussed in this article.

\section{References}

1. Barbosa-Ferreira JM, Fernandes F, Dabarian A, Mady C. Leptin in heart failure. Expert Opin Med Diagn. 2013;7(1):113-117. doi:10.1517/17530059.2013.735229

2. Dădârlat-Pop A, Sitar-Tăut A, Zdrenghea D, et al. Profile of obesity and comorbidities in elderly patients with heart failure. Clin Interv Aging. 2020;15:547-556. doi:10.2147/CIA.S248158

3. Iwai M, Horiuchi M. Role of renin-angiotensin system in adipose tissue dysfunction. Hypertens Res. 2009;32(6):425-427. doi:10.1038/ hr.2009.55

4. Alpert MA, Karthikeyan K, Abdullah O, Ghadban R. Obesity and Cardiac Remodeling in Adults: mechanisms and Clinical Implications. Prog Cardiovasc Dis. 2018;61(2):114-123. doi:10.1016/j.pcad.2018.07.012

5. Szabó T, Scherbakov N, Sandek A, et al. Plasma adiponectin in heart failure with and without cachexia: catabolic signal linking catabolism, symptomatic status, and prognosis. Nutr Metab Cardiovasc Dis. 2014;24(1):50-56. doi:10.1016/j.numecd.2013.04.015

6. Packer M. Leptin-Aldosterone-Neprilysin Axis: identification of Its Distinctive Role in the Pathogenesis of the Three Phenotypes of Heart Failure in People With Obesity. Circulation. 2018;137 (15):1614-1631. doi:10.1161/CIRCULATIONAHA.117.032474

7. Chow SL, Maisel AS, Anand I, et al. Role of Biomarkers for the Prevention, Assessment, and Management of Heart Failure: a Scientific Statement From the American Heart Association. Circulation. 2017;135(22):e1054-e1091. doi:10.1161/ CIR.0000000000000490

8. Piek A, Du W, de Boer RA, Sillje HHW. Novel heart failure biomarkers: why do we fail to exploit their potential? Crit Rev Clin Lab Sci. 2018;55(4):246-263. doi:10.1080/10408363.2018.1460576

9. Gehlken C, Suthahar N, Meijers WC, de Boer RA. Galectin-3 in Heart Failure: an Update of the Last 3 Years. Heart Fail Clin. 2018;14(1):75-92. doi:10.1016/j.hfc.2017.08.009

10. Shah RV, Truong QA, Gaggin HK, Pfannkuche J, Hartmann O, Januzzi JL. Mid-regional pro-atrial natriuretic peptide and pro-adrenomedullin testing for the diagnostic and prognostic evaluation of patients with acute dyspnoea. Eur Heart J. 2012;33 (17):2197-2205. doi:10.1093/eurheartj/ehs136

11. Farooqi IS, O'Rahilly S. 20 years of leptin: human disorders of leptin action. J Endocrinol. 2014;223(1):T63-70. doi:10.1530/JOE-14-0480

12. Menini S, Iacobini C, Blasetti Fantauzzi C, Pesce CM, Pugliese G. Role of Galectin-3 in Obesity and Impaired Glucose Homeostasis. Oxid Med Cell Longev. 2016;2016:9618092. doi:10.1155/2016/ 9618092

13. Mishra A, Srivastava A, Kumar S, et al. Role of angiotensin II type I (AT1 A1166C) receptor polymorphism in susceptibility of left ventricular dysfunction. Indian Heart J. 2015;67(3):214-221. doi:10.1016/j.ihj.2015.04.013

14. Dadarlat A, Pop D, Procopciuc L, Buzoianu A. Links between renin-angiotensin system genetic polymorphisms and leptin secretion in obese heart failure patients. Acta Endo. 2018;14(2):274-279. doi:10.4183/aeb.2018.274

15. Ponikowski P, Voors AA, Anker SD, et al. 2016 ESC Guidelines for the diagnosis and treatment of acute and chronic heart failure: the Task Force for the diagnosis and treatment of acute and chronic heart failure of the European Society of Cardiology (ESC) Developed with the special contribution of the Heart Failure Association (HFA) of the ESC. Eur Heart J. 2016;37(27):2129-2200. doi:10.1093/eurheartj/ehw128
16. Dadarlat A, Pop D, Farcas AD, et al. Can the presence of atrial fibrillation influence the levels of heart failure - specific biomarkers in overweight and obese patients with heart failure?, Rev. Chim. 2019;70(6):2294-2300.

17. Takemoto Y, Sakatani M, Takami S, et al. Association between angiotensin II receptor gene polymorphism and serum angiotensin converting enzyme (SACE) activity in patients with sarcoidosis. Thorax. 1998;53(6):459-462. doi:10.1136/thx.53.6.459

18. Wolk R, Somers VK. Leptin and vascular function: friend or foe? Eur Heart J. 2006;27(19):2263-2265. doi:10.1093/eurheartj/ehl246

19. Berzabá-Evoli E, Zazueta C, Cruz Hernández JH, et al. Leptin modifies the rat heart performance associated with mitochondrial dysfunction independently of its prohypertrophic Effects. Int $J$ Endocrinol. 2018;2018:6081415. doi:10.1155/2018/6081415

20. Wannamethee SG, Shaper AG, Whincup PH, Lennon L, Papacosta O, Sattar N. The obesity paradox in men with coronary heart disease and heart failure: the role of muscle mass and leptin. Int $J$ Cardiol. 2014;171(1):49-55. doi:10.1016/j.ijcard.2013.11.043

21. Nasri H. Serum leptin concentration and left ventricular hypertrophy and function in maintenance hemodialysis patients. Minerva Urol Nefrol. 2006;58(2):189-193.

22. Khafaji HA, Bener AB, Rizk NM, Al Suwaidi J. Elevated serum leptin levels in patients with acute myocardial infarction; correlation with coronary angiographic and echocardiographic findings. $B M C$ Res Notes. 2012;5(1):262. doi:10.1186/1756-0500-5-262

23. Van Berendoncks AM, Garnier A, Ventura-Clapier R, Conraads VM. Adiponectin: key role and potential target to reverse energy wasting in chronic heart failure. Heart Fail Rev. 2013;18(5):557-566. doi:10.1007/s10741-012-9349-4

24. Deswal A. Obesity, leptin, and incident heart failure. $J$ Am Coll Cardiol. 2011;58(18):1878-1880. doi:10.1016/j.jacc.2011.07.030

25. Lieb W, Sullivan LM, Harris TB, et al. Plasma leptin levels and incidence of heart failure, cardiovascular disease, and total mortality in elderly individual. Diabetes Care. 2009;32(4):612-616. doi: $10.2337 / \mathrm{dc} 08-1596$

26. Castellano M, Glorioso N, Cusi D, et al. Genetic polymorphism of the renin-angiotensin- aldosterone system and arterial hypertension in the Italian population: the GENIPER Project. J Hypertens. 2003;21 (10):1853-1860. doi:10.1097/00004872-200310000-00012

27. Baudin B. Polymorphism in angiotensin II receptor genes and hypertension. Exp Physiol. 2005;90(3):277-282. doi:10.1113/ expphysiol.2004.028456

28. Głuszek J, Jankowska K. Is there relationship between the A1166C polymorphism of the angiotensin II receptor AT1 and plasma renin activity, insulin resistance and reduction of blood pressure after angiotensin-converting enzyme inhibitor therapy? Pol Arch Med Wewn. 2008;118(4):194-200.

29. Pop D, Zdrenghea D, Procociuc LM, Popa A. Gene polymorphism of angiotensin- converting enzyme and angiotensin II type 1 receptor in patients with congestive heart failure. Rom J Intern Med. 2007;45 (4):349-354.

30. Pop D. Sistemul Renină-Angiotensină-Aldosteron În Patogeneza Bolilor Cardiovasculare. Ed. Clusium. Cluj-Napoca; 2007.

31. Mishra A, Srivastava A, Mittal T, Garg N, Mittal B. Genetic predisposition to left ventricular dysfunction: a multigenic and multi-analytical approach. Gene. 2014;546(2):309-317. doi:10.1016/ j.gene.2014.05.060

32. Pintérová L, Zelezná B, Ficková M, et al. Elevated AT1 receptor protein but lower angiotensin II-binding in adipose tissue of rats with monosodium glutamate-induced obesity. Horm Metab Res. 2001;33 (12):708-712. doi:10.1055/s-2001-19132

33. French B, Wang L, Ky B, et al. Prognostic value of galectin-3 for adverse outcomes in chronic heart failure. J Card Fail. 2016;22 (4):256-262. doi:10.1016/j.cardfail.2015.10.022 


\section{Publish your work in this journal}

The International Journal of General Medicine is an international, peer-reviewed open-access journal that focuses on general and internal medicine, pathogenesis, epidemiology, diagnosis, monitoring and treatment protocols. The journal is characterized by the rapid reporting of reviews, original research and clinical studies across all disease areas. The manuscript management system is completely online and includes a very quick and fair peer-review system, which is all easy to use. Visit http://www.dovepress.com/ testimonials.php to read real quotes from published authors.

Submit your manuscript here: https://www.dovepress.com/international-journal-of-general-medicine-journal 